\title{
Antifungal activity of lipopeptides from endophytic strains of the genus Bacillus sp. against the fungus
} Stagonospora nodorum (Berk.)

Sarvarova E.R., Cherepanova E.A., Maksimov I.V.

Institute of Biochemistry and Genetics - Subdivision of the Ufa Federal Research Centre of the Russian Academy of Sciences, Ufa, Russia E-mail: sarvarova_lena@mail.ru

Key message. The direct antibiotic effect of lipopeptides from four endophytic strains on the germination of spores of the pathogenic fungus Stagonospora nodorum (Berk.) was found and the minimum inhibitory concentration (MIC) of these lipopeptides was determined.

Keywords: endophytes, lipopeptides, antifungal activity, Basillus, Stagonospora nodorum (Berk.)

Endophytic bacteria are able to stimulate plant growth and exhibit antifungal properties and therefore they are interesting as a basis for the creation of biological agents to protection. [Maximov et al., 2011].

Various antimicrobial metabolites, such as lipopeptide biosurfactants, especially lipopeptides from bacteria of the genus Bacillus, allow to suppress and destroy pathogenic microorganisms, and also affect the antifungal ability of the strain at different concentrations [Li et al, 2019].

The MIC values of metabolites that lead to maximum inhibition of fungal spore growth allow us to see differences in the ability of different strains to inhibit the growth of pathogens [Hua et al., 2014]. In this regard, the purpose of our research is to determine the MIC of lipopeptides from four endophytic strains.

In order to determine the MIC of lipopeptides, fungi spores were washed away from the surface of $S$. nodorum mycelium grown on potatoglucose agar (PGA) in Petri dishes. In 96-well plates under sterile conditions, different concentrations of lipopeptides from B. subtilis 26D, B. subtilis 11BM, B. subtilis Ts1 and B. subtilis Ts8-2 in a 1: 100 ratio were added to the spore suspension. Lipopeptides were used in the following concentrations: $0,50,100,150,200,250,300 \mu \mathrm{g} / \mathrm{ml}$. Spores were incubated at $28^{\circ} \mathrm{C}$ for $1 \mathrm{~h}$. Then, the spores were transferred to Petri dishes with PGA and cultured at $28{ }^{\circ} \mathrm{C}$ for 2 days, then the minimum lipopeptide concentration of each bacterial strain which leads to inhibition of fungal growth was determined.

The MIC of B. subtilis 26D, B. subtilis $11 \mathrm{BM}$ and B. subtilis Ts8-2 lipopeptides was $150 \mu \mathrm{g} / \mathrm{ml}$, of B. subtilis Ts1 - $100 \mu \mathrm{g} / \mathrm{ml}$. Thus, the lipopeptides synthesized by B. subtilis Ts1 strain are characterized by higher antifungal activity compared to the lipopeptides of the other strains. The obtained results allow us to conclude about similar negative effect of lipopeptides of various strains of endophytic bacteria on the growth of $S$. nodorum fungus, however, their biocidal activity may vary. A study of the composition of lipopeptides may explain some differences in the properties of the studied endophytic bacterial strains, which will contribute to the development of more effective microbiological plant protection products.

This research was funded by the grant of the Russian Foundation for Basic Research № 17-29-08014.

\section{Антифунгальная активность липопептидов из эндофитных штаммов рода Bacillus sp. против гриба} Stagonospora nodorum (Berk.)

Сарварова Е.Р., Черепанова Е.А., Максимов И.В.

Институт биохимии и генетики - обособленное структурное подразделение Уфимского федерального исследовательского центра РАН, Уфа, Россия

Аннотация. Выявлен антибиотический эффект липопептидов из четырех эндофитных штаммов на прорастание спор фитопатогенного гриба Stagonospora nodorum (Berk.) и определена минимальная ингибируюшая конщентрация (МИК) данных липопептидов.

Ключевые слова: эндофиты, липопептиды, антифунгальная активность, Basillus, Stagonospora nodorum (Berk.)

Эндофитные бактерии способны стимулировать рост растений и проявлять антифунгальные свойства и поэтому представляют большой интерес в качестве основы для создания биологических средств защиты. [Максимов и др., 2011].

Различные антимикробные метаболиты, такие как липопептидные биосурфактанты, особенно характерные для бактерий рода Bacillus, позволяют подавлять и уничтожать патогенные микроорганизмы, а также в различных концентрациях влияют на антифунгальную способность штамма [Li et al, 2019].

Значения МИК метаболитов, приводящие к максимальному ингибированию роста спор грибов позволяют увидеть различия в способности различных штаммов подавлять рост патогенов [Hua et al., 2014]. В связи с этим была поставлена цель - определить МИК липопептидов из четырех эндофитных штаммов.

Для определения МИК липопептидов делали смыв спор грибов с поверхности выращенного на картофельно-глюкозном агаре (КГА) в чашках Петри мицелия S. nodorum. В 96-луночных планшетах в стерильных условиях к суспензии спор добавляли различные концентрации липопептидов из B. subtilis 26Д, B. subtilis 11BM, B. subtilis Ts1 и B. subtilis Ts8-2 в соотношении 1:100. Липопептиды применялись в следующих концентрациях: 0, 50, 100, 150, 200, 250, 300 мкг/мл. Споры инкубировали при $28^{\circ} \mathrm{C}$ в течение 1 ч. Затем споры переносили на чашки Петри с КГА и культивировали при $28^{\circ} \mathrm{C}$ в течение 2 суток, после чего определяли минимальную концентрацию липопептидов каждого штамма бактерий, приводящую к ингибированию роста гриба.

МИК липопептидов B. subtilis 26Д, B. subtilis 11 ВМ и B. subtilis Тs8-2 составила 150 мкг/мл, для B. subtilis Тs1- 100 мкг/мл. Таким образом, липопептиды, синтезируемые штаммом B. subtilis Ts1, характеризуются большей антифунгальной активностью, по сравнению с липопептидами остальных штаммов. Полученные результаты позволяют сделать вывод о сходном негативном влиянии липопептидов различных штаммов эндофитных бактерий на рост гриба S. nodorum, однако их биоцидная активность может отличаться. Изучение состава продуцируемых липопептидов может объяснить некоторые отличия в свойствах изученных эндофитных штаммов бактерий, что будет способствовать разработке более эффективных микробиологических средств защиты растений.

Работа выполнена при финансовой поддержке гранта РФФИ-офим № 17-29-08014.

1. Li Y., Wang, R., Liu J., Xu L., Ji P., Sun L., Pan H., Jiang B., Li L. Identification of a biocontrol agent Bacillus vallismortis BV23 and assessment of effects of its metabolites on Fusarium graminearum causing corn stalk rot // Biocontrol Sci. Technol. - 2019. - V. 29 (3). P. 263-275.

2. Hua H., Xing F., Selvaraj, J., Wang, Y., Zhao Y., Zhou L., Liu X., Liu Y. Inhibitory effect of essential oils on Aspergillus ochraceus growth and ochratoxin A production // PloS One. - 2014. - V. 9 (9). - e108285.

3. Максимов И. В., Абизгильдина Р. Р., Пусенкова Л. И. Стимулирующие рост растений микроорганизмы как альтернатива химическим средствам защиты от патогенов (обзор) // Прикладная биохимия и микробиология. - 2011. - Т. 47 (4), - С. $373-385$. 